\title{
University of Wollongong
}

Masthead Logo Research Online

Faculty of Science, Medicine and Health - Papers:

part A

Faculty of Science, Medicine and Health

2015

\section{A cross-sectional comparison of health literacy deficits among patients with chronic kidney disease}

Kelly Lambert

University of Wollongong, klambert@uow.edu.au

Judy Mullan

University of Wollongong, jmullan@uow.edu.au

Kylie J. Mansfield

University of Wollongong, kylie@uow.edu.au

Maureen A. Lonergan

Illawarra Shoalhaven Local Health District, maureenl@uow.edu.au

\section{Publication Details}

Lambert, K., Mullan, J., Mansfield, K. \& Lonergan, M. (2015). A cross-sectional comparison of health literacy deficits among patients with chronic kidney disease. Journal of Health Communication: international perspectives, 20 (Suppl. 2), 16-23.

Research Online is the open access institutional repository for the University of Wollongong. For further information contact the UOW Library: research-pubs@uow.edu.au 


\title{
A cross-sectional comparison of health literacy deficits among patients with chronic kidney disease
}

\begin{abstract}
Inadequate health literacy in people with chronic kidney disease (CKD) is associated with poorer disease management and greater complications. There are limited data on the health literacy deficits of people with CKD. The aim of this study was to investigate the types and extent of health literacy deficits in patients with CKD using the multidimensional Health Literacy Management Scale (HeLMS) and to identify associations between patient characteristics and the domains of health literacy measured by the HeLMS. Invitations to participate were sent to patients with CKD attending the renal unit of a regional Australian hospital. These patients included predialysis, dialysis (peritoneal and hemodialysis), and kidney transplant patients. This study identified that inadequate health literacy-especially in the domains relating to attending to one's health needs, understanding health information, social support, and socioeconomic factors-was common. Male gender and education level were significantly associated with inadequate health literacy. The type and extent of health literacy deficits varied among CKD groups, and transplant patients had more deficits than other $\mathrm{CKD}$ patient groups. This study provides useful information for health professionals treating patients with $\mathrm{CKD}$, especially with regard to the design of self-management interventions and health information.
\end{abstract}

\section{Disciplines}

Medicine and Health Sciences | Social and Behavioral Sciences

\section{Publication Details}

Lambert, K., Mullan, J., Mansfield, K. \& Lonergan, M. (2015). A cross-sectional comparison of health literacy deficits among patients with chronic kidney disease. Journal of Health Communication: international perspectives, 20 (Suppl. 2), 16-23. 
Article Title: A cross sectional comparison of health literacy deficits among patients with chronic kidney disease.

Article running title: Health literacy deficits among patients with chronic kidney disease.

\section{Abstract}

Inadequate health literacy in people with chronic kidney disease (CKD) is associated with poorer disease management and greater complications. There is limited data on the health literacy deficits of people with CKD. The aim of this study was to investigate the types and extent of health literacy deficits in patients with CKD using the multidimensional Health Literacy Management Scale (HeLMS) and to identify associations between patient characteristics and the domains of health literacy measured by the HeLMS. Invitations to participate were sent to patients with CKD attending the renal unit of a regional Australian hospital. These patients included predialysis, dialysis (peritoneal and haemodialysis) and kidney transplant patients. This study identified that inadequate health literacy; especially in the domains relating to attending to one's health needs, understanding health information, social support and socioeconomic factors, was common. Male gender and education level were significantly associated with inadequate health literacy. The type and extent of health literacy deficits varied between CKD groups and transplant patients had more deficits than other CKD patient groups. This study provides useful information for health professionals treating patients with CKD, especially with regards to the design of self-management interventions and health information. 
Keywords: health literacy, chronic kidney disease, end stage kidney disease, self management, patient education, HeLMS 


\section{Main text:}

\section{Introduction}

Chronic Kidney Disease (CKD) is becoming increasingly common globally due to the growing prevalence of diabetes mellitus, hypertension, obesity and ageing (Avodele and Alebiosu, 2010). CKD progresses to end stage kidney disease (ESKD) in around $2 \%$ of cases (Anderson et al., 2009), and requires treatment such as dialysis, kidney transplant or symptom management only. In Australia, it is predicted that current health services will be unable to meet the increasing demand to care for the growing number of CKD patients who will progress to ESKD (AIHW, 2014; Cass et al., 2010). In addition, treatments for those with ESKD who require dialysis or a kidney transplant are expensive. In 2010, the cost to the Australian Government of providing dialysis and transplantation services was estimated to be almost \$1 billion AUD (Cass et al., 2010).

Strategies to reduce the progression of CKD to ESKD have centred on modifying lifestyle related behaviours (Curtin et al., 2008; Chen et al., 2011). These lifestyle related behaviour changes include: improving medication adherence (e.g. to antihypertensive and/or diabetic medications); avoiding nephrotoxic agents (e.g. non-steroidal anti-inflammatory medications); and adopting positive selfmanagement behaviours (e.g. smoking cessation, weight reduction, a reduction in salt and protein intake, and increasing physical activity levels) (Johnson and Atai et al., 2013)). Unfortunately, the recommendations for lifestyle related behaviour changes are complex and have not translated into meaningful reductions in the progress from CKD to ESKD (Jain and Reilly, 2014). 
Health literacy is defined as 'the cognitive and social skills which determine the motivation and ability of individuals to gain access to, understand, and use information in ways that promote and maintain good health' (Nutbeam ,1998). Adequate health literacy $(\mathrm{HL})$ is considered a critical but often overlooked skill set required by individuals with CKD. This skill set is considered essential for compliance with the lifestyle related behaviour changes required for effective self-management and prevention of the progression of CKD (Selden et al., 2000; Becker, 2009; Dageforde and Cavanaugh., 2013; Fraser et al., 2013, Meyer, 2014). Unfortunately, inadequate health literacy is common in individuals with CKD. A recent systematic review involving six studies with a total of 1,405 patients (mostly of patients receiving haemodialysis from the USA) estimated the overall prevalence of inadequate health literacy in these patients as approximately 23\% (Fraser et al, 2013).

Inadequate health literacy in individuals with CKD is associated with worse health outcomes (Devraj and Gordon, 2009). These negative outcomes include poorer control of biochemical parameters (Vourakis et al., 2012); worse cardiovascular disease (CVD) risk profiles (Ricardo et al., 2014); greater numbers of missed haemodialysis treatments and higher rates of hospitalisation (Green et al., 2013); reduced rates of referral for kidney transplantation (Grubbs et al., 2009); poorer peritoneal dialysis performance and higher rates of infection (Kleinpeter, 2003; Jain et al., 2015), as well as overall higher rates of mortality (Cavanaugh et al., 2010).

Measurement of health literacy levels in individuals with CKD have mostly relied on using one-dimensional tools to measure one aspect of health literacy, such as numeracy or reading comprehension (Devraj et al., 2015; Jain et al., 2014; Jain et 
al., 2015; Ricardo et al., 2014; Kazley et al., 2015; Green et al., 2011). There is little health literacy data available for individuals with CKD measured using multidimensional health literacy tools. There are also only limited studies investigating whether patients with CKD have barriers to finding, understanding and using health information. The Health Literacy Measurement Scale (HeLMS) (Jordan, 2009) is a multidimensional health literacy assessment tool that was developed and validated in the Australian setting that captures these health literacy elements.

The aims of this research were to (i) utilise the HeLMS to explore the type and extent of health literacy deficits that people with CKD exhibit and (ii) to explore any associations between inadequate health literacy and patient characteristics, such as age, gender, duration of dialysis or transplant and years of education.

\section{Methods}

This study was approved by the University of [removed for blinded peer review] Health and Medical Human Research Ethics Committee.

\section{Participants and recruitment}

Invitations to participate in the study were sent to adult patients ( $\geq 18$ years of age)

with CKD $(n=366)$ attending the renal unit of a large regional Australian hospital. This was restricted to four groups of CKD patients, which included the pre-dialysis patients, those receiving peritoneal dialysis, those receiving haemodialysis and those who had undergone a kidney transplant. Patients with dementia or known cognitive 
impairment, as determined by their treating renal physician, were excluded from the study.

\section{Demographic details}

Information regarding patient characteristics such as age, gender, educational level, and comorbid chronic disease burden were obtained from the patient records where available. Details regarding the presence of other chronic disease were limited to the presence of lung disease, coronary artery disease, peripheral vascular disease, diabetes, cardiovascular disease and cancer. These chronic diseases were chosen because this information is routinely collected for all patients receiving renal replacement therapy in Australia (i.e. dialysis or transplant) (ANZDATA, 2015).

\section{Assessment of Health Literacy}

The Health Literacy Management Scale (HeLMS) was used to assess the health literacy of study participants. The HeLMS consists of 29 subjectively rated questions to assess health literacy that are divided into eight health literacy domains (Table 1). Five of the HeLMS domains focus on the individual's abilities (domains 2,5-8), and three of the HeLMS domains (domains 1, 3 and 4) focus on broader factors, such as attitudes, social support and socio-economic factors, all of which could impact on health literacy (Jordan, 2009).

The HeLMS tool was administered in the renal unit after receiving informed consent from the patient. For those receiving haemodialysis, the HeLMS was administered during the patient's haemodialysis session within the renal unit. Professional interpreter services were used to complete the assessment with patients who could not communicate in English. 
Statistical analyses

Statistical analysis was performed using SPSS Statistics for Windows version 19, (SPSS, Chicago, IL, USA). The Shapiro-Wilk Test was used to assess normality. Independent samples t-tests or ANOVA were used and data is reported as means and standard deviations (SD). Categorical variables, expressed as counts and percentages (\%), were also evaluated using Pearson's Chi Square with Bonferroni's post hoc test for multiple comparisons.

Analysis of the HeLMS data was undertaken according to the methods suggested by Briggs et al, 2011 and Jordan, 2009. Responses to the 29 items within the eight domains of the HeLMS (Table 1) were scored on a five point Likert scale. To calculate the proportion of individuals with inadequate health literacy, responses were dichotomised as either 'no difficulty' (i.e. a score of 5 on the Likert scale) or 'any difficulty' (i.e. a score of 1-4 on the Likert scale). If a statistically significant difference was identified for a particular domain within the HeLMS, then further analyses of the responses to the individual items within that domain were undertaken.

Logistic regression was conducted to determine the relationship between relevant statistically significant HeLMS domains or individual items within relevant HeLMS domains using covariates of age, gender, years of education, duration and type of renal replacement therapy. These covariates have been identified previously as predictors of low health literacy in patients with ESKD (Fraser et al, 2013). 


\section{Results}

\section{Participant characteristics}

In total, 153 individuals (59.5\% male) with CKD volunteered to participate in the study (overall response rate of $42 \%$ ) with the majority of them having less than 12 years of schooling (56.2\%) and being in either the haemodialysis (34\%) or transplant group (34\%) (Table2). The mean age of the participants was 64.1 years with patients in the transplant group being significantly younger (56.4 years) than the others. The dialysis (peritoneal and haemodialysis) and renal transplant patients had received their renal replacement therapy for a mean duration of 6.12 years, with the transplant patients having received their treatment for a significantly longer period of time (10.44 years), as compared to the dialysis patients. It is also important to note that the pre-dialysis group had very advanced kidney disease as highlighted by their low mean estimated Glomerular Filtration Rate (eGFR) of $11.9 \mathrm{ml} / \mathrm{min}$ (Table 2).

Information regarding comorbid disease burden was not available for 39 participants including all of the pre-dialysis participants. The available data regarding selected comorbid disease(s) burden (Table 3) indicates that half of the participants had more than three chronic diseases. There were significant differences between the groups regarding the number of chronic diseases $(p<0.05)$ with the haemodialysis group having a greater proportion of patients with Coronary Artery Disease, Peripheral Vascular Disease and a greater number of individuals with more than three chronic conditions, as compared to the transplant patients. The transplant patients were significantly more likely to have cancer compared to the peritoneal dialysis patients. 


\section{HeLMS domain scores of health literacy}

The participants' mean scores for the eight HeLMS domains are displayed in Table 4. Results were also included in the table for individual items within domains 1 and 2 which had mean scores of four or less or were found to be statistically significant. The only items with a mean score of 4 or less for each of the groups, included domain 1 [item 7- change your lifestyle to improve your health] and domain 1 [item 23- find the energy to manage your health]. The scores for these items were not statistically significantly different between the groups. Further, analysis of the data indicated a significant difference between the patient groups for domain 2 [Understanding health information], especially between the pre-dialysis and the transplant groups $(p<0.05)$. Statistically significant differences were also apparent between the groups for domain 2 [item 14- filling in forms], domain 2 [item 20reading written information] and domain 2 [item 27- finding health information]. Transplant patients and haemodialysis patients had significantly lower scores, compared to pre-dialysis patients, for domain 2 [14- filling in forms]. However, haemodialysis patients scored significantly better than transplant patients for domain 2 [27- finding health information]. In addition, pre-dialysis patients scored significantly higher for domain 2 [20- reading written information], as compared to transplant patients.

\section{Proportion of participants with CKD and inadequate health literacy}

Results in Figures 1 and 2 are reported as the proportion of participants with scores indicative of inadequate health literacy. This was calculated by dichotomising the data, 'no difficulty' (score =5) or with 'any difficulty' (scores $\leq 4$ ). Figure 1 indicates 
that there were statistically significant differences between the groups for domain 2 (Understanding health information). For this domain, pre-dialysis patients had the lowest proportion with inadequate health literacy. For domain 1 (Patient attitudes towards their health) well over $40 \%$ of the patients in all groups had inadequate health literacy in this domain, and about one third of all patients demonstrated inadequate health literacy for domain 4 (socio-economic factors for accessing healthcare services). Patients in all groups had the lowest proportions of inadequate health literacy for domain 5 (accessing GP, health care services) and domain 8 (using health information). Furthermore, pre-dialysis patients in particular had the highest proportion of inadequate health literacy for domain 3 (social support).

Further analysis of the individual HeLMS items within these domains was undertaken (Figure 2). This analysis indicated that there were statistically significant differences in proportions with inadequate health literacy between the four groups for the following: domain 1 [item 7- changing lifestyle to improve health]; domain 2 [item 14 filling in forms], domain 2 [item 20 - reading written information], and domain 2 [item 27 - finding health information] (Figure 2). Pre-dialysis patients were statistically less likely to have inadequate health literacy deficits for each of these items, except for domain 2 [item 27 - finding health information]. However, transplant patients were significantly more likely to have inadequate health literacy for domain 2 [item 27 finding health information]. In addition to these statistically significant results, items of potential clinical importance include domain 1 [item 23 - finding the energy to manage their health] and 2 [9 - read health information]. For domain 1 [item 23 finding the energy to manage their health] over $60 \%$ of the dialysis (peritoneal and haemodialysis) and transplant patients had inadequate health literacy. Whereas, for 
domain 2 [item 9 - read health information] over $20 \%$ of the dialysis (peritoneal and haemodialysis) and transplant patients had inadequate health literacy. For each of these items the pre-dialysis patients had the lowest proportion with inadequate health literacy.

Predictors of Inadequate Health Literacy

Logistic regression analyses indicated that male gender and less than 12 years of education were statistically significant predictors of inadequate health literacy for HeLMS domain items 2 [14 - filling in forms] and 2 [20 - reading written health information] (Table 5). Less than 12 years of education was also a statistically significant predictor of inadequate health literacy for domain 2 [item 27 - finding health information]. Age and the patient's duration of renal replacement therapy did not appear to be significant predictors of inadequate health literacy for these items.

\section{Discussion}

The findings in this study provide evidence on several aspects of health literacy in an Australian cohort of individuals with chronic kidney disease. Firstly, a high proportion of individuals with CKD had scores suggestive of inadequate health literacy for (domain 1) attitudes towards their health and (domain 4) socioeconomic factors. This study highlighted that transplant patients, even though significantly younger than the other participants, exhibited the greatest number of health literacy deficits, and that male gender and less than 12 years of education were predictors of inadequate health literacy for understanding health information.

Findings from the current study indicate that over $40 \%$ of participants in all four groups reported difficulty with their attitudes towards health (domain 1). This is of 
concern because unless they are able to effectively self-manage their lifestyle behaviours it is highly likely that they will experience progression of their CKD and/or poor health outcomes. It is also important to note that many CKD patients will have multiple chronic diseases that they need to also self-manage (such as those seen in our study). It is suggested therefore, that patient attitudes towards their health be addressed in the design of self-management programs and CKD patient education. There is also a need for further research to investigate the efficacy of nosogological approaches to improve the ability of patients with CKD to attend to their health needs (Ballerini and Paris, 2006).

In the present study, approximately one in every four participants in the dialysis and transplant groups exhibited difficulties understanding health information (domain 2). This is consistent with qualitative research conducted by Sakraida and Robinson (2009) who identified that self-management was limited by the participants' difficulties finding and utilising health information. This was reportedly due to message confusion or discrepancies between the information content provided and information that was desired by patients with CKD. Other research in a larger group of patients with CKD had reported that difficulties understanding health information may also be the result of the resources focusing too heavily on clinical outcomes rather than practical support (Tong et al, 2009). The potential impact of the difficulties dialysis and especially transplant patient's face in understanding health information and the impact of this on their treatment choices is unknown and remains an area for future research. 
Another important finding in this study was that participants in the pre-dialysis group appear to have less difficulties finding and understanding health information as compared to those participants receiving renal replacement therapy (e.g. dialysis or a transplant). Even though reasons for this finding are unknown, one could speculate that this may be an example of a previously cited suspicion that pre-dialysis patients ‘don't know what they don't know' (Ormandy, 2008, p25). Alternatively, it may be that these participants are predominantly 'information receivers' and only acquire knowledge in a passive manner as a way of coping with their kidney disease (Bonner and Lloyd, 2011). Further research is required to clarify these differences between the pre-dialysis patients and those receiving renal replacement therapy..

Education level is commonly associated with inadequate health literacy in CKD (Fraser et al, 2013). In the present study more than $50 \%$ of the patients with CKD had less than 12 years of education and more than three additional chronic diseases. This may partly explain our results that many of the participants reported difficulties finding and understanding health information. A recent systematic review was conducted on the comprehensibility of patient education material targeted at individuals with CKD (Morony et al, 2015). The results indicated that most publicly available resources for people with CKD were written at a level exceeding the 'average' patient and were beyond the readability level appropriate for individuals with low literacy. Achieving a degree of understanding about CKD as well as the other chronic diseases a person may have is likely to be challenging in individuals with low literacy. Further research on how people with CKD (especially those with multiple chronic diseases) find health information, as well as research evaluating the 
sources and quality of health information for patients with CKD could better inform future interventions.

The current study has identified that social support (domain 3) and socioeconomic factors (domain 4) are important issues for pre-dialysis patients and all patients with CKD, respectively. This is consistent with previous research in the CKD context where social support and socioeconomic resources are considered paramount to the success of self-management (especially for transplant patients) (Browne and Merigi, 2010; Fraser et al., 2013). Health professionals need to also consider these health literacy elements when providing services and information to patients with CKD.

The authors acknowledge there are several limitations to this study that may impact on the generalisability of results. These include the cross sectional nature of the research; using relatively small patient numbers from a single local health district; and unequal numbers between patient groups. There was also incomplete data on the comorbid disease burden for approximately $25 \%$ of participants in this study, which according to the literature may impact on health literacy in CKD (Green et al, 2011). Another limitation of this study was the use of the HeLMS (Jordan, 2009), which has been recently superseded by the Health Literacy Questionnaire (Osborne et al, 2013).

Despite these limitations, it is evident that inadequate health literacy, measured using a multidimensional tool, was common amongst this cohort of patients with CKD and should be of concern to health professionals. Importantly, evidence from this preliminary study has highlighted that there are a number of gaps in the current evidence about the impact that inadequate health literacy can have on a CKD patient's progression to ESKD. 


\section{Conclusion}

This study identified that inadequate health literacy, especially in the domains relating to attending to one's health needs, understanding health information, social support and socioeconomic factors were common for CKD patients. The type and extent of health literacy deficits varied between CKD groups, with transplant patients having the largest proportion of health literacy deficits. This study provides useful considerations for health professionals when providing care for CKD patients, especially with regards to self-management strategies, support and access to reliable and easy to understand health information. Future efforts should be directed to address these potential barriers to effective self management and optimal health outcomes.

\section{References:}

Anderson, S.A, Halter, J.B., Hazzard, W.R., Himmelfarb, J., McFarland Horne, F., Kaysen, G.A. et al. Prediction, progression and outcomes of chronic kidney disease in older adults. Journal of the American Society of Nephrology, 20,1199-1209.

ANZDATA Registry. (2015). 37th Report, Chapter 1: Incidence of End Stage Kidney

Disease. Australia and New Zealand Dialysis and Transplant Registry, Adelaide, Australia. Retrieved from: http://www.anzdata.org.au

Australian Institute of Health and Welfare (AlHW). (2014). Projections of the prevalence of treated end-stage kidney disease in Australia 2012-2020. Cat. no. PHE 176. Canberra: AlHW.

Avodele, O.E., and Alebiosu, C.O. (2010). Burden of chronic kidney disease: an international perspective. Advances in Chronic Kidney Disease. 17,215-224. 
Ballerini, L and Paris, V. (2006). Nosogogy: when the learner is a patient with chronic renal failure. Kidney International.103;_S122-6.

Becker, B.N. (2009). Focusing on Health Literacy Might Help Us Cross the Quality Chasm. American Journal of Kidney Diseases. 53, 730-732.

Briggs, A.M., Jordan, J.E., O'Sullivan, P.B., Buchbinder, R., Burnett, A.F., Osborne, R.H. et al (2011). Individuals with chronic low back pain have greater difficulty in engaging in positive lifestyle behaviours than those without back pain: An assessment of health literacy. BMC Musculoskeletal Disorders. 12,161.

Bonner, A., Lloyd, A. (2012) Exploring the information practices of people with end stage kidney disease. Journal of Renal Care. 38(3);124-130.

Browne, T., and Merigi. J., R. (2010) Barriers to Adult Hemodialysis Patients' SelfManagement of Oral Medications American Journal of Kidney Diseases. 56:547557.

Burke, M.T., Kapojos, J., Sammartino, C., Gray, N.A. (2014). Kidney disease health literacy among new patients referred to a nephrology outpatient clinic. Internal Medicine Journal. 44(11);1080-6

Cass, A., Chadban,S., Gallagher, M., Howard, K., Jones, A., McDonald, S. et al. (2010). The Economic Impact of End-Stage Kidney Disease in Australia: Projections to 2020. Kidney Health Australia. Melbourne, Victoria.

Cavanaugh, K.L., Wingard, R.L., Hakim, R.M., Eden, S., Shintani, A., Wallston, K.A. et al (2010). Low Health Literacy Associates with Increased Mortality in ESRD, Journal of the American Society of Nephrology. 21,1979-1985. 
Chen, S.H., Tsai, Y.F., Sun, C.Y., Wu, I.W., Lee, C.C, Wu, M.S. (2011). The impact of self-management support on the progression of chronic kidney disease-a prospective randomized controlled trial. Nephrology Dialysis Transplantation, 26, 3560-3566.

Clark, S., Farrington, K., and Chilcot, J. (2014). Non adherence in Dialysis Patients: Prevalence, Measurement, Outcome, and Psychological Determinants. Seminars in Dialysis. 27(1); 42-49.

Curtin, .R.B., Walters, B.A., Schatell, D., Pennell, P., Wise, M., Klicko, K. (2008). Self-efficacy and self-management behaviours in patients with chronic kidney disease. Advances in Chronic Kidney Disease, 15,191-205.

Dageforde, L.A. and Cavanaugh, K.L. (2013). Health Literacy: Emerging Evidence and Applications in Kidney Disease Care. Advances in Chronic Kidney Disease. 20,311-319.

Devraj, R., Borrego, M., Vilay, A.M., Gordon, E.J., Pailden, J., Horowitz, B. (2015). Relationship between health literacy and kidney function. Nephrology, doi: 10.1111/nep.12425. [Epub ahead of print]

Devraj, R. And Gordon, E.J. (2009). Health Literacy and Kidney Disease: Toward a New Line of Research. American Journal of Kidney Diseases. 53,884-889.

Fraser, S., Roderick, P.J., Casey, M., Taal, M.W., Yuen, H.M. and Nutbeam, D. (2013). Prevalence and associations of limited health literacy in chronic kidney disease: a systematic review. Nephrology Dialysis Transplantation,28, 129-137. Green, J.A., Mor, M.K., Shields, A.M., Sevick, M.A., Palevsky, P.M. Fine, M.J et al. (2011). Prevalence and Demographic and Clinical Associations of Health Literacy in 
Patients on Maintenance Hemodialysis. Clinical Journal of the American Society of Nephrology. . 6(6),1354-1360.

Green, J.A., Mor, M.K., Shields, A.M., Sevick, M.A., Arnold, R.M, Palevsky, P.M. et al (2013). Associations of health literacy with dialysis adherence and health resource utilization in patients receiving maintenance haemodialysis. American Journal of Kidney Diseases. 62(1); 73-80.

Grubbs, V., Gregorich, S.E., Perez-Stable, E.J., Hsu, C-Y (2009). Health literacy and access to kidney transplantation. Clinical Journal of the American Society of Nephrology. .4(1): 195-200.

Jain, D., Sheth, H., Bender, F.H., Weisbord, S.D.,Green, J.A., (2014). Evaluation of a Single-Item Screening Question to Detect Limited Health Literacy in Peritoneal Dialysis Patients. Advances in Peritoneal Dialysis. 30, 27-30.

Jain, D., Sheth, H., Green, J.A., Bender, F.H., Weisbord, S.D. (2015). Health Literacy in Patients on Maintenance Peritoneal Dialysis: Prevalence and Outcomes. Peritoneal Dialysis International.32, 96-98.

Jain, N. and Reilly, R.F. (2014). Effects of dietary interventions on incidence and progression of CKD. Nature Reviews Nephrology, 10(12), 712-714.

Johnson, D.W., Atai, E., Chan, M., Phoon, R.K.S., Scott, C., Toussaint, N.D. et al. (2013). KHA-CARI guideline: Early chronic kidney disease: detection, prevention and management. Nephrology; 18(5), 340-50.

Jordon, J.E (2009). Conceptualising and measuring health literacy from the patient perspective. University of Melbourne, Department of Medicine, 2009. 
Kazdin, A.E. (1999) The Meanings and Measurement of Clinical Significance.

Journal of Consulting and Clinical Psychology. 67; 332-339.

Kazley, A.S., Jordon, J., Simpson, K.N, Chavin, K., Baliga, P. (2015). Health literacy and kidney transplant outcomes. Progress in Transplantation. 25, 85-90.

Kleinpeter, M. A., (2003). Health literacy affects peritoneal dialysis performance and outcomes. Advances in Peritoneal Dialysis. 19,115-119.

Lloyd, A., Bonner, A., Dawson-Rose, C. (2014). The health information practices of people living with chronic health conditions: implications for health literacy. Journal of Librarianship and Information Science. 46;207-216.

Meyer, G. (2014). Chronic kidney disease: who is affected, who is at risk and who cares? Nephrology Dialysis Transplantation.29(5),937-941.

Morony, S., Flynn, M., McCaffery, K.J., Jansen, J., Webster, A.C. (2015). Readability of Written Materials for CKD Patients: A systematic review. American Journal of Kidney Diseases. Early View Article in Press, DOI:

http://dx.doi.org/10.1053/j.ajkd.2014.11.025

Nutbeam, D. (1998). Health promotion glossary. Health Promotion International. 13, 349-364.

Ormandy, P. (2008). Information topics important to chronic kidney disease patients: a systematic review. Journal of Renal Care. 34(1):19-27.

Osborne, R., Batterham, R.W., Elsworth, G.R., Hawkins, M., and Buchbinder, R. (2013). The grounded psychometric development and initial validation of the Health Literacy Questionnaire (HLQ). BMC Public Health. 13, 658. 
Ricardo, A.C., Yang, W., Lora, C.M., Gordon, E.J., Diamantidis, C.J., Ford, V. Et al (2014). Limited health literacy is associated with low glomerular filtration in the Chronic Renal Insufficiency Cohort (CRIC) study. Clinical Nephrology. 81;30-37. Selden, C., Zorn, M., Ratzan, S., Parker, R. (2000). National Library of Medicine current bibliographies in medicine: Health literacy. NLM Pub. No. CBM 2000-1. Bethesda, MD: National Institutes of Health, U.S. Department of Health and Human Services.

Sakraida, T.J. and Robinson, M.V. (2009). Health Literacy Self- Management by Patients With Type 2 Diabetes and Stage 3 Chronic Kidney Disease. Western Journal of Nursing Research. 31, 627-647.

Skelton, S.L., Waterman, A.D., Davis, A.A., Peipert, J.D., Fish, A.F. (2015). Applying best practices to designing patient education for patients with end stage renal disease pursuing kidney transplant. Progress in Transplantation. 25, 77-85.

Tong, A., Sainsbury, P., Chadbhan, S., Walker, R.G., Harris, D.C., Carter, S.M et al. (2009).Patients' experiences and perspectives of living with CKD. American Journal of Kidney Diseases. 53; 689-700.

Vourakis et al. (2012). Health Literacy is Associated with Higher Serum Phosphate Levels in Urban Haemodialysis Patients. American Journal of Kidney Diseases, 59, B24. 
Table 1.Description of the domains of the HeLMS (adapted from Briggs et al, 2011 and Jordan, 2009).

\begin{tabular}{|c|c|c|}
\hline Domain & Domain title & Domain description \\
\hline 2 & Understanding health information & $\begin{array}{l}\text { This domain focuses on an individual's ability to access and understand different } \\
\text { formats of health information [Items } 9,14,20,27] \text {. }\end{array}$ \\
\hline 3 & Social support & $\begin{array}{l}\text { This domain assesses an individual's ability to seek social support to manage } \\
\text { their health. Social support refers to family, friends and broader community } \\
\text { networks [Items } 11,15,21,28] \text {. }\end{array}$ \\
\hline 4 & $\begin{array}{l}\text { Socioeconomic factors for } \\
\text { accessing healthcare services }\end{array}$ & $\begin{array}{l}\text { This domain covers broader socioeconomic circumstances of an individual (ie } \\
\text { financial resources) to be able to access health information and services [Items } \\
16,18,24] \text {. }\end{array}$ \\
\hline 5 & $\begin{array}{l}\text { Accessing General Practitioner (GP) } \\
\text { healthcare services }\end{array}$ & $\begin{array}{l}\text { This domain is concerned with an individual's ability to access healthcare services } \\
\text { and knowing where to seek health information [Items } 10,12,22,29] \text {. }\end{array}$ \\
\hline 7 & Being proactive & $\begin{array}{l}\text { This domain focuses on an individual's ability to proactively seek and understand } \\
\text { information about their health [Items } 3,6,25] \text {. }\end{array}$ \\
\hline 8 & Using health information & $\begin{array}{l}\text { This domain refers to an individual's ability to understand and use information to } \\
\text { make informed health decisions to maintain their health [Items } 1,5,8,26] \text {. }\end{array}$ \\
\hline
\end{tabular}


Table 2: Characteristics of study participants $(n=153)$.

\begin{tabular}{|c|c|c|c|c|c|}
\hline Patient characteristics & $\begin{array}{c}\text { Pre-dialysis } \\
\text { group } \\
n=24\end{array}$ & $\begin{array}{c}\text { Peritoneal Dialysis } \\
\text { group } \\
n=25\end{array}$ & $\begin{array}{l}\text { Haemodialysis } \\
\text { group } \\
\mathrm{n}=52\end{array}$ & $\begin{array}{l}\text { Transplant } \\
\text { group } \\
n=52 \\
\end{array}$ & $\begin{array}{l}\text { Total } \\
\mathrm{n}=153 \\
\end{array}$ \\
\hline $\begin{array}{l}\text { Age (years), } \\
\text { mean (SD) }\end{array}$ & $68.0(10.9)$ & $69.5(13.2)$ & $67.3(14.6)$ & $56.4(12.9)$ * & 64.1 (14.3) \# \\
\hline $\begin{array}{l}\text { Estimated Glomerular } \\
\text { Filtration Rate (ml/min), } \\
\text { mean (SD) }\end{array}$ & $11.9(4.7)$ & N/A & N/A & $58.3(18.3)$ & $43.1(26.7)$ \\
\hline $\begin{array}{l}\text { Duration of renal } \\
\text { replacement therapy, years } \\
\text { mean (SD) }\end{array}$ & $\mathrm{N} / \mathrm{A}$ & $2.94(1.8)$ & $6.1(5.4)$ & $10.44(9.0)$ * & 6.12 (7.2) \# \\
\hline $\begin{array}{l}\text { Less than } 12 \text { years of } \\
\text { education, } \mathrm{n}(\%)\end{array}$ & $13(54.2)$ & $18(72.0)$ & $32(61.5)$ & $23(44.2)$ & $86(56.2)$ \\
\hline Male, n (\%) & $11(45.8)$ & $16(64.0)$ & $28(53.9)$ & $36(69.2)$ & $91(59.5)$ \\
\hline
\end{tabular}

$\# \mathrm{p}<0.05$, ANOVA

* indicates significantly different from all other groups.

Renal replacement therapy indicates receival of dialysis or transplantation

N/A not applicable 
Table 3.Comorbid disease burden of study participants $(n=114)$.

\begin{tabular}{|c|c|c|c|c|c|}
\hline & $\begin{array}{c}\text { Pre-dialysis } \\
\text { group } \\
n=0\end{array}$ & $\begin{array}{l}\text { Peritoneal } \\
\text { Dialysis } \\
\text { group } \\
n=20 \\
\end{array}$ & $\begin{array}{c}\text { Haemodialysis } \\
\text { group } \\
n=45\end{array}$ & $\begin{array}{c}\text { Transplant } \\
\text { group } \\
n=49\end{array}$ & $\begin{array}{l}\text { Total } \\
n=114\end{array}$ \\
\hline Lung disease, $\mathrm{n}(\%)$ & $\mathrm{n} / \mathrm{a}$ & $3(15.0)$ & $12(26.7)$ & $8(16.3)$ & $23(20.2)$ \\
\hline Coronary Artery Disease, n (\%) & $\mathrm{n} / \mathrm{a}$ & $8(40.0)$ & $27(60.0)^{a}$ & $13(26.5)^{a}$ & $48(42.1) \#$ \\
\hline Peripheral Vascular Disease n (\%) & $\mathrm{n} / \mathrm{a}$ & $4(20.0)$ & $26(57.8)^{b}$ & $16(32.7)^{b}$ & $46(40.4) \#$ \\
\hline Diabetes, n (\%) & $\mathrm{n} / \mathrm{a}$ & $7(35.0)$ & $23(51.1)$ & $14(28.6)$ & $44(38.6)$ \\
\hline Cardiovascular Disease, $\mathrm{n}(\%)$ & $\mathrm{n} / \mathrm{a}$ & $2(10.0)$ & $14(31.1)$ & $8(16.3)$ & $24(21.1)$ \\
\hline Cancer, n (\%) & $\mathrm{n} / \mathrm{a}$ & $1(5.0)^{c}$ & $9(20.0)$ & $17(34.7)^{c}$ & $27(23.7) \#$ \\
\hline More than 3 chronic diseases, n (\%) & $\mathrm{n} / \mathrm{a}$ & $9(45.0)$ & $32(71.1)^{d}$ & $16(32.6)^{d}$ & $57(50.0) \#$ \\
\hline
\end{tabular}

\# p<0.05; Values with same superscript (a, b, c, d) are significantly different. 
Table 4: Mean HeLMS scores for each domain and relevant items for study participants.

\begin{tabular}{|c|c|c|c|c|c|c|}
\hline $\begin{array}{l}\text { Domain } \\
\text { [item] }\end{array}$ & Domain descriptor & $\begin{array}{l}\text { Pre-dialysis } \\
\text { group } \\
n=24\end{array}$ & $\begin{array}{l}\text { Peritoneal } \\
\text { Dialysis } \\
\text { group } \\
n=25 \\
\end{array}$ & $\begin{array}{c}\text { Haemodialysis } \\
\text { group } \\
n=52\end{array}$ & $\begin{array}{c}\text { Transplant } \\
\text { group } \\
n=52 \\
\end{array}$ & $\begin{array}{l}\text { Total } \\
n=153\end{array}$ \\
\hline 1 & $\begin{array}{l}\text { Patient attitudes towards their } \\
\text { health }\end{array}$ & $3.92(0.77)$ & $4.11(0.72)$ & $3.99(0.79)$ & $4.06(0.86)$ & $4.02(0.79)$ \\
\hline 1 [Item 7] & $\begin{array}{l}\text { Change your lifestyle to improve } \\
\text { your health }\end{array}$ & $3.62(0.92)$ & $4(1.19)$ & $3.69(1.17)$ & $3.94(1.12)$ & $3.81(1.12)$ \\
\hline 1 [Item 23] & $\begin{array}{l}\text { Find the energy to manage your } \\
\text { health }\end{array}$ & $3.67(1.05)$ & $3.68(1.25)$ & $3.73(1.03)$ & $3.94(1.04)$ & $3.78(1.06)$ \\
\hline 2 & Understanding health information & $4.88(0.30)^{a}$ & $4.37(1.12)$ & $4.53(0.76)$ & $4.36(0.92)^{a}$ & $4.5(0.85) \#$ \\
\hline 2 [Item 9] & $\begin{array}{l}\text { Read health information brochures } \\
\text { found in hospitals eg at a Dr clinic }\end{array}$ & $4.91(0.28)$ & $4.28(1.2)$ & $4.51(1.08)$ & $4.48(0.91)$ & $4.53(0.97)$ \\
\hline 2 [Item 14] & Fill in forms eg Medicare & $4.96(0.20)^{b, c}$ & $4.36(1.29)$ & $4.21(1.18)^{b}$ & $4.17(1.28)^{\mathrm{c}}$ & $4.34(1.16) \#$ \\
\hline 2 [Item 20] & $\begin{array}{l}\text { Read written information given to } \\
\text { you eg by a Doctor }\end{array}$ & $4.95(0.20)^{d}$ & $4.32(1.22)$ & $4.56(1.06)$ & $4.35(1.05)^{d}$ & $4.51(1.01) \#$ \\
\hline 2 [Item 27] & $\begin{array}{l}\text { Find health information in a } \\
\text { language you can understand }\end{array}$ & $4.67(0.87)$ & $4.52(1.09)$ & $4.84(0.36)^{\mathrm{e}}$ & $4.42(0.87)^{\mathrm{e}}$ & $4.62(0.79) \#$ \\
\hline 3 & Social support & $4.23(0.85)$ & $4.61(0.61)$ & $4.51(0.74)$ & $4.61(0.62)$ & $4.52(0.71)$ \\
\hline 4 & Socioeconomic factors & $4.38(0.70)$ & $4.49(0.71)$ & $4.47(0.73)$ & $4.31(0.90)$ & $4.40(0.78)$ \\
\hline 5 & Accessing GP services & $5(0.0)$ & $4.91(0.31)$ & $4.96(0.15)$ & $4.88(0.37)$ & $4.93(0.27)$ \\
\hline 6 & $\begin{array}{l}\text { Communication with health } \\
\text { professionals }\end{array}$ & $4.76(0.66)$ & $4.33(1.08)$ & $4.71(0.65)$ & $4.66(0.56)$ & $4.64(0.71)$ \\
\hline 7 & Being proactive & $4.62(0.73)$ & $4.53(0.89)$ & $4.37(0.97)$ & $4.47(0.78)$ & $4.47(0.86)$ \\
\hline
\end{tabular}


\# $p<0.05$; Values with same superscript (a, b, c, d, e) are significantly different (one way ANOVA).

Scores $\leq 4$ suggest inadequate health literacy. 
Table 5.Results from logistic regression for factors associated with inadequate health literacy for selected HeLMS items.

\begin{tabular}{|l|c|c|c|c|}
\hline HeLMS domain [item] & Age & Male gender & $\begin{array}{c}\text { Duration RRT } \\
\text { Less than 12 years } \\
\text { of education }\end{array}$ \\
\hline $\begin{array}{l}\text { 1 [Item 7] Change your lifestyle to } \\
\text { improve your health }\end{array}$ & $0.98(0.96-1.02)$ & $1.4(0.67-2.901)$ & $0.96(0.90-1.01)$ & $1.4(0.67-2.91)$ \\
\hline $\begin{array}{l}1 \text { IItem 23] Find the energy to } \\
\text { manage your health }\end{array}$ & $0.99(0.97-1.02)$ & $1.17(0.57-2.43)$ & $0.94(0.89-0.99)$ & $1.82(0.86-3.84)$ \\
\hline $\begin{array}{l}2 \text { [Item 14] Fill in forms eg Medicare } \\
\text { 2 [Item 20] Read written information } \\
\text { given to you eg by a Doctor }\end{array}$ & $0.98(0.95-10.2)$ & $3.19(1.09-9.34) *$ & $0.96(0.89-1.04)$ & $6.77(2.17-21.08)^{\star}$ \\
\hline $\begin{array}{l}\text { 2 [Item 27] Find health information in } \\
\text { a language you can understand }\end{array}$ & $0.99(0.03-1.04)$ & $2.08(0.51-8.55)$ & $0.95(0.86-1.06)$ & $4.93(1.15-21.08) *$ \\
\hline
\end{tabular}

Abbreviations: RRT: renal replacement therapy (ie dialysis or transplantation); ${ }^{p}<<0.01$ 